\title{
Awareness Investigation about Hearing Conservation Program of the Employee Who Work in Noisy Environments
}

\author{
Sungil Park, Kookhwa Kim, Danvi Kim, Jiyeon Kim, Jieun Han \\ Department of Speech Pathology Therapy and Aural Rehabilitation, Woosong University, Daejeon, Korea \\ 소음환경에서 근무하는 사람들의 청력보존프로그램에 대한 인식 조사 \\ 박성일 · 김국화 · 김단비 · 김지연 · 한지은 \\ 우송대학교 언어치료청각재활학부
}

\begin{abstract}
Purpose: This study was performed to establish the effective hearing conservation program for noisy industries. Methods: A total of 100 employees who were working in noisy environments participated. Subjects were divided into four groups according to the size of firms and the periods of noise exposure. A 12-question survey related to factors of the hearing conservation program was designed and assessed. Results: Results showed that all participants perceived the importance of hearing conservation. There were significant differences among four groups in the awareness level of the importance of hearing protection. Employees who were working at a big firm and had more than ten years of noise exposure experiences were more aware of factors related to hearing protection than others. Conclusion: Awareness of the hearing protection of hearing protection needs to be the most important factor in establishing and operating hearing conservation program. Further research should be considered in light of the outcome of this study.
\end{abstract}

Key Words: Noise induced hearing loss, Hearing conservation program, Awareness of hearing protection.

Received: September 2, 2016 / Revised: October 2, 2016 / Accepted: October 5, 2016

Correspondence: Sungil Park, Department of Speech Pathology Therapy and Aural Rehabilitation, Woosong University, 171 Dongdaejeon-ro, Dong-gu, Daejeon 34606, Korea

Tel: +82-42-630-9224 / Fax: +82-42-630-9229 / E-mail: psiyes@naver.com

\section{INTRODUCTION}

괴롭고 원치 않는 혹은 정신적, 육체적으로 인체에 유해한 큰 소리를 소음이라 하는데 이러한 소음에 의해서 발생하는 감 각성 난청을 '소음성 난청(noise-induced hearing loss)'이라고 한다. 소리를 감지하는 기관 즉, 코르티기관이 총체적으로 파괴 된 경우이며 특히 고주파를 감지하는 감각세포가 주로 손상받 게 된다. $85 \mathrm{dBA}$ 이상 매우 강한 소음에 지속적으로 노출될 때 난청이 발생되며 소음에 의한 달팽이관의 유모세포의 손상 은 일시적인 손상에 대해서는 대부분 회복이 가능하지만 오랜 기간 소음에 지속되거나 수용 한도를 넘는 폭음에 노출되면 유 모세포는 회복이 불가능할 정도로 손상된다(Kwon, 2010). 소 음성 난청은 어음역에서 순음청력손실평균이 중등도를, 고음역 에서 최소가청역치가 고도 이상을 초과하지 않아 초기의 경우
조기발견이 어렵고 일단 저주파수 대역까지 난청이 진행된 다 음에는 치료방법이 없을 만큼 조기 진단과 예방이 특히 중요하 다. 소음성 난청의 증상으로는 이명으로부터 고통을 받고, 가 족이나 친구 및 동료와의 의사소통이 잡음 환경에서 어려움이 있어 삶이 질적으로 저하될 수도 있다. 의사소통장애로 인해 사회적 고립감에 시달리며, 불안감, 예민해짐, 자존감의 저하 등 의 심리적 문제를 야기하게 된다. 또한 작업환경에 위험신호나 장비소리에 대한 감시능력저하에 따른 손상의 증가로 인해 근 로자보상비용이 증가하며 이는 궁극적으로 생산성 저하로 이어 지게 된다. 심한 경우 맥박과 혈압에도 영향을 주며 소화 장애 및 자율신경계의 이상도 초래한다(Lee, 2010).

소음성 난청은 최근 직업병 유소견자 중에서 가장 높은 비 율을 차지하고 있으며, 산업의 기계화가 가속됨으로써 소음성 난청환자의 발생 문제는 더욱 심각해질 전망이다(Kim, 2006). 
그렇기 때문에 소음폭로 근로자들의 청력보존을 위한 대책이 시급한 실정이다. 산업현장에서의 청력보존프로그램(Hearing Conservation Program, $\mathrm{HCP}$ )은 작업장에서 과다한 소음에 노출되는 근로자들에게서 발생할 수 있는 소음성 난청을 예방 하기 위하여 수행하는 프로그램이다. 1983년부터 미국 산업안 전보건청(Occupational Safety and Health Administration)은 일일 8 시간 평균 $90 \mathrm{dBA}$ 를 넘을 때는 소음제어를 실시하고, 85 $\mathrm{dBA}$ 를 넘을 때는 청력보존프로그램 실시를 권장하고 있다. 청 력보존프로그램은 소음 측정, 공학적 소음제어와 행정적 관리, 청력보호구 착용, 청력검사 및 의학적 판정, 보건교육 및 훈련, 기록보관 및 프로그램 효과 평가 등 7개의 구성요소로 되어 있 다(Kwak et al., 1997).

우리나라에서 작업환경 중 소음수준이 1995 2000년의 조 사 결과 소음의 노출기준 초과율이 1995년의 39.7\%에서 2000 년의 $26.5 \%$ 로 감소추세에 있으나 유해인자 중 가장 높은 초과 율로 나타났으며(Lee, 2010) 한국산업안전공단 산업안전보건연 구원에서 건강진단결과 소음성 난청으로 인한 직업병 유소견자 의 수도 1999년 1,056건, 2000년 1,368건, 2001년 1,330건, 2002년 2,000건으로 4년간 2.4배 증가한 것으로 보고된 바 있 다. 그러나 현실적으로 작업장에서 소음이 발생하는 위험요소 를 원천적으로 없애는 것은 불가능한 일이다. 귀마개와 같은 청 력보호구를 착용하게 하여 소음의 노출 정도를 감소시키려고 하고 있으나 작업 중 불편하여 많은 근로자들이 잘 착용하지 않고 있고 소음이 인체에 미치는 심각성을 제대로 인식하지 못 하기 때문에 소음 작업장에서의 근무를 크게 불편해하지 않고 있다. 따라서 소음 환경에서 근무하는 근로자들에 대한 소음성 난청의 예방 및 소음의 위험성, 소음 작업장의 환경관리 및 청 력보존프로그램의 중요성을 근로자 본인들이 스스로 인지할 수 있도록 알려주는 것이 중요하다(Choi \& Lee, 1996).

기업규모에서 대기업은 자본에 대한 지원이나 사회적인 인식 등에 따라 근로자들의 환경개선에 투자를 많이 한다. 그 방면 으로 소음성 난청 예방을 위한 $\mathrm{HCP}$ 도 함께 진행하고 있다. 하 지만, 대기업에 비해 중소기업은 근무 환경이 좋지 않고, 소음 성 난청 예방에 대한 부분은 법적인 절차만 지키는 부분이 많 아 소음성 난청 유병환자의 증가를 초래할 가능성도 있다. 청 력보존프로그램에 대한 부분은 대기업과 중소기업 모두 실시 하고는 있으나 두 기업의 인식 비교 연구는 많이 이루어지고 있 지 않기 때문에 본 연구에서는 대기업과 중소기업의 소음환경 에서 근무하는 근로자들의 소음성 난청에 대한 인식 및 청력보 존프로그램에 대한 인식 현황을 비교 연구하고자 한다. 또한, 이를 통해 우리나라 소음발생 산업장에서 근무하는 근로자들 의 소음성 난청을 예방하기 위한 체계적인 교육 프로그램을 개 선·개발하는 것에 기여하고자 한다.

\section{MATERIALS AND METHODS}

\section{연구 대상}

중견기업 성장촉진 및 경쟁력 강화에 관한 특별법 시행령에 의거한 중소기업과 중견기업의 요건에 해당하지 않는 대기업의 사업장 근로자들 중 하루 8시간 평균 소음이 $85 \mathrm{dBA}$ 이상인 소 음부서에서 근무하고 있는 근로자들을 대상으로 하였고 소음 측정은 각 기업의 안전관리 팀장으로부터 정보를 획득하였다.

\section{연구 방법}

근로자 분류는 대기업 근로자 50명(I군)과 노동자 수 300 명 미만의 중소기업 제조업 근로자 50명(II군)으로 선정하였다. 검 사에 참여한 근로자들에게 조사의 목적과 개요를 설명하고 검 사 참여에 동의를 구한 후 설문지를 각 기관으로 보냈다. 공군 작업자들의 소음 폭로와 관련된 위험 인지(Kang, 2000)의 설 문지를 참고하였으며, 공학적 또는 관리적 소음 조절 부분의 문 항을 추가하였다. 기존 설문지의 수정으로 인해 신뢰도 검증을 하였다. 신뢰도 검증은 크론바흐 알파값(Cronbach's $\alpha$ )으로 하 였고, 그 값은 0.86 으로 본 설문지를 사용해도 적절한 것으로 보였다. 설문 문항은 청력보존프로그램의 5 개 구성요소(1) 소 음측정, (2) 공학적 또는 관리적 소음 조절, (3) 교육, (4) 청력보 호, (5) 청력측정)를 중심으로 설정하였다(Table 1). 소음측정과 관련되는 2 개 문항(나는 내가 일하고 있는 부서의 소음 수준을 알고 있다, 소음 방지 및 청력보호를 위해 소음 측정을 할 필요 가 있다), 공학적 또는 관리적 소음 조절과 관련되는 1 개 문항 (소음 속 근로시간의 추가에 따른 쉬는 시간이 제공되거나 교 대근무를 한다), 교육과 관련되는 3 개의 문항(나는 청력보호에 대한 교육을 받은 적이 있다, 나는 소음에 대한 교육을 받은 적 이 있다, 우리나라 산업안전보건법상 8시간 동안 작업을 할 때 소음의 허용기준은?), 청력보호와 관련되는 1 개 문항(나는 귀마 개를 지급받은 적이 있다), 청력측정과 관련되는 2 개 문항(나는 지금까지 청력검사를 받은 적이 있다, 나는 청력검사에서 귀가 나쁘다고 애기 들은 적이 있다), 기타 3 개 문항(소음이 건강에 미치는 해로운 영향이 얼마 동안 폭로되었을 때 발생한다고 생 각하십니까?, 나는 귀 때문에 진료를 받은 적이 있다, 직업병은 예방 가능하다)으로 총 12 문항으로 설문지를 작성하였다. 설문 은 네이버 폼 온라인 설문 응답 프로그램을 이용하여 기관으로 전송하여 설문조사를 실시하였다. 설문조사는 2016년 1월 10 일부터 5월 30 까지 총 5 개월 동안 실시하였으며, 근로자가 직접 기록하는 것을 원칙으로 하였다. 본 연구에서는 대기업 소음부 서 근로자들(I군)과 중소기업 소음부서 근로자들(II군), 대기업 에서 10년 이하 근무한 근로자들(I-I군)과 10년 초과 근무한 근로자들(I-II군), 중소기업에서 10년 이하 근무한 근로자들(II 
Table 1. Questionnaire about perception of hearing conservation

\begin{aligned} & \hline No. \\ & \hline 1 I know the noise level of the department where I work. \\ & 2 It is necessary to measure the noise for hearing protection \\ & 3 I have had earplugs \\ & 4 I have had medical treatment because of ear \\ & 5 I have had hearing test \\ & 6 I have heard that hearing protection is possible from regular hearing test \\ & 7 I have had education about hearing protection \\ & 8 I have had education about noise \\ & 9 When working during 8 hours in Korea by a Korean Occupational Safety and Health Act, what is permitted levels of noise? \\ & 10 Occupational diseases are preventable \\ & 11 Do you think you can get health damaging when you expose to noise for several hours? \\ & 12 Can you have the shift of working position or working break if you work additional hours in a noisy environment? \\ & \hline\end{aligned}

Table 2. Comparison of large firms and medium enterprises

\begin{tabular}{|c|c|c|c|c|c|c|}
\hline & \multicolumn{2}{|r|}{ Large firms } & \multicolumn{2}{|c|}{ Medium enterprises } & \multirow{2}{*}{$t$ value } & \multirow{2}{*}{$p$ value } \\
\hline & Mean & Standard deviation & Mean & Standard deviation & & \\
\hline Noise measurement awareness & 77 & 12.2 & 41 & 13.1 & $t=-3.010$ & $p<0.05$ \\
\hline Hearing measurement awareness & 54 & 13.4 & 59 & 12.6 & $t=-1.002$ & $p>0.05$ \\
\hline Hearing protect awareness & 50 & 14.2 & 43 & 12.4 & $t=-2.120$ & $p<0.05$ \\
\hline Education awareness & 82 & 13.2 & 24 & 12.5 & $t=-7.261$ & $p<0.05$ \\
\hline Engineering and managemnt noise control awareness & 68 & 13.8 & 46 & 12.7 & $t=-3.280$ & $p<0.05$ \\
\hline Total awareness & 64.00 & 13.4 & 33.83 & 12.3 & $t=-4.030$ & $p<0.05$ \\
\hline
\end{tabular}

$-\mathrm{I}$ 군)과 10 년 초과 근무한 근로자들(II-I군)을 비교군으로 하 였다.

\section{통계 처리}

두 점수 집합 간 평균의 차가 통계적으로 유의미한지의 여부 를 살펴보고자 $t$ 검정 통계적 분석법을 사용하였다. Levene의 등분산 검정의 유의확률 값이 0.05 이상, 평균의 동일성에 대한 $t$ 검정의 유의확률 값이 0.05 이하일 때 평균 간 차이가 통계적 으로 유의미한 것으로 본다.

\section{RESULTS}

본 연구는 소음 속에서 근무하는 대상자가 작성한 청력보존 프로그램 인식 설문지를 대기업, 중소기업으로 분류하여 결과 를 도출하였다. 본 설문조사에 앞서 성별, 나이, 회사명, 근로년 수에 대해 질문하였다. 설문 결과를 기반으로 대기업과 중소기 업의 청력보존프로그램에 대한 인식을 비교하였고, 근로년수에 따른 인식 정도를 비교하였다.

설문지는 대기업에 종사하는 사람 50 명, 중소기업에 종사하 는 사람 50 명으로 총 100 명이 응답하였다. 설문 결과, 대기업은 남자 $88 \%$, 여자 $12 \%$ 로, 중소기업은 남자 $100 \%$ 로 응답하였고, 연령별로 대기업 20 대 $24 \%, 30$ 대 $42 \%, 40$ 대 $24 \%$, 50대 $10 \%$ 가
응답하였고, 중소기업 20대 50\%, 30대 $42.9 \%, 40$ 대 $7.1 \%$ 로 응 답하였다.

\section{대기업, 중소기업 전체 청력보존프로그램 인식 설문 결과}

Table 2의 대기업과 중소기업의 청력보존프로그램에 대한 전 체 인식 비교에서는 대기업은 평균 64.00이었고, 중소기업은 평 균 33.83으로 나타나 대기업과 중소기업의 근로자들이 청력보 존프로그램에 대한 인식 부분에서 통계적으로 유의미한 차이를 보였다 $(t=-4.030, p<0.05)$.

청력보존프로그램 인식 설문지를 대기업과 중소기업에 따라 문항별로 분석한 결과, 소음측정 관련 문항(나는 내가 일하고 있는 부서의 소음수준을 알고 있다, 소음방지 및 청력보호를 위해 소음 측정을 할 필요가 있다)에서 대기업은 '예' $77 \%$, '아 니오' 23\%, 중소기업은 ‘예' $41 \%$, '아니오' $59 \%$ 로 응답하였고 통 계적으로 유의미한 차이를 보였다 $(t=-3.010, p<0.05)$. 하지만 청력측정 관련 문항(나는 지금까지 청력검사를 받은 적이 있다) 에서 대기업은 '예' $54 \%$, '아니오' $46 \%$, 중소기업은 '예' $59 \%$, '아 니오' $41 \%$ 로 응답하여 통계적으로 유의미한 차이를 보이지 않 았다 $(t=-1.002, p>0.05)$. 청력보호 관련 문항(나는 귀마개를 지급 받은 적이 있다)에서 대기업은 '예' $50 \%$, '아니오' $50 \%$, 중 소기업은 ‘예' $43 \%$, '아니오' $57 \%$ 로 응답하였고 통계적으로 유 의미한 차이를 보였다 $(t=-2.120, p<0.05)$. 교육 관련 문항(나 
는 청력보호에 대한 교육을 받은 적이 있다, 나는 소음에 대한 교육을 받은 적이 있다, 우리나라 산업안전보건법상 8시간동안 작업을 할 때 소음의 허용 기준은?)에서 대기업은 '예' $82 \%$, '아 니오' $18 \%$, 중소기업은 '예' $24 \%$, '아니오' $76 \%$ 로 응답하였으며 통계적으로 유의미한 차이를 보였다 $(t=-7.261, p<0.05)$. 교육 문항 중 '우리나라 산업안전보건법상 소음의 허용 기준은?'에 대한 응답으로 대기업은 ' $80 \mathrm{~dB}$ ' $56 \%$, '90 dB' $44 \%$, 중소기업은 '80 dB' 14\%, '90 dB' 28\%, '100 dB' 39\%, '120 dB' 17\%로 응답 하였다. 공학적 또는 관리적 소음조절 관련 문항(소음 속 근로 시간 추가에 따른 쉬는 시간이 제공되거나 교대근무를 하십니 까?)에서 대기업은 '예' $68 \%$, '아니오' $32 \%$, 중소기업은 '예' $46 \%$, '아니오' $54 \%$ 로 응답하였고 통계적으로 유의미한 차이를 보였다 $(t=-3.280, p<0.05)$. 기타 문항(나는 귀 때문에 진료 를 받은 적이 있다, 직업병은 예방 가능하다)에서 대기업은 '예' $53 \%$, '아니오' $47 \%$, 중소기업은 '예' $57 \%$, '아니오' $43 \%$ 로 응답 하였다. 기타 문항 중 '소음이 건강에 미치는 해로운 영향이 얼 마동안 폭로되었을 때 발생한다고 생각합니까?'에 대한 응답으 로 대기업은 '아주 잠시 폭로되어도 해롭다' $8 \%$, '수 시간 이상 폭로되면 해롭다' $44 \%$, '수 일 이상 폭로되면 해롭다' $16 \%$, '수 년 이상 폭로되면 해롭다' $10 \%$, '십여년 이상 폭로되면 해롭다' $22 \%$, 중소기업은 '아주 잠시 폭로되어도 해롭다' $10 \%$, '수 시간 이상 폭로되면 해롭다' $42 \%$, '수 일 이상 폭로되면 해롭다' $17 \%$, '수 년 이상 폭로되면 해롭다' $28 \%$, '십여 년 이상 폭로되면 해 롭다' $0 \%$ 로 응답하였다.

\section{근무년수별 청력보존프로그램 인식 설문 결과}

Table 3은 근무년수 10년을 기준으로 나누었을 경우 인식차 이를 나타낸 것이다. 먼저 청력보존프로그램 인식 설문지를 10 년 이하 근무자를 기업별로 분석한 결과, 대기업은 평균 58.00 이었고, 중소기업은 45.66으로 나타나 통계적으로 유의미한 차 이를 보이지 않았다 $(t=-1.442, p>0.05)$. 각 문항별로 분석한 부분을 보면 소음측정 관련 문항(나는 내가 일하고 있는 부서 의 소음수준을 알고 있다, 소음방지 및 청력보호를 위해 소음 측정을 할 필요가 있다)에서 대기업 근로자는 '예' $63 \%$, '아니오' $37 \%$, 중소기업 근로자들은 '예' $50 \%$, '아니오' 50\%로 응답하였 다. 청력측정 관련 문항(나는 지금까지 청력검사를 받은 적이 있다)에서 대기업 근로자들은 '예' $54 \%$, '아니오' $46 \%$, 중소기업 근로자들은 '예’ $61 \%$, '아니오' $39 \%$ 로 응답하였다. 청력보호 관
련 문항(나는 귀마개를 지급 받은 적이 있다)에서 대기업 근로 자들은 '예' $37 \%$, '아니오' $63 \%$, 중소기업 근로자들은 '예' $43 \%$, ‘아니오' $57 \%$ 로 응답하였다. 교육 관련 문항(나는 청력보호에 대한 교육을 받은 적이 있다, 나는 소음에 대한 교육을 받은 적 이 있다, 우리나라 산업안전보건법상 8시간동안 작업을 할 때 소음의 허용 기준은?)에서 대기업 근로자들은 '예' $81 \%$, '아니 오' $19 \%$, 중소기업 근로자들은 '예’ $17 \%$, '아니오' $83 \%$ 로 응답하 였다. 교육 문항 중 '우리나라 산업안전보건법상 소음의 허용 기 준은?'에 대한 응답으로 대기업 근로자들은 ' $80 \mathrm{~dB}$ ' $50 \%$, '90 $\mathrm{dB}$ ' $50 \%$, 중소기업 근로자들은 ' $80 \mathrm{~dB}$ ' $8 \%$, '90 dB' 30\%, '100 $\mathrm{dB}$ ' $40 \%$, ' $120 \mathrm{~dB}$ ' 21\%로 응답하였다. 공학적 또는 관리적 소 음조절 관련 문항(소음 속 근로시간 추가에 따른 쉬는시간이 제공되거나 교대근무를 하십니까?)에서 대기업 근로자들은 '예' $58 \%$, '아니오' $42 \%$, 중소기업 근로자들은 '예' $48 \%$, '아니오' $52 \%$ 로 응답하였다. 기타 문항(나는 귀 때문에 진료를 받은 적 이 있다, 직업병은 예방 가능하다, 소음이 건강에 미치는 해로 운 영향이 얼마동안 폭로되었을 때 발생한다고 생각하십니까?) 에서 대기업 근로자들은 '예' $55 \%$, '아니오' $45 \%$, 중소기업 근로 자들은 '예' $55 \%$, '아니오' $45 \%$ 로 응답하였다. 기타 문항 중 '소 음이 건강에 미치는 해로운 영향이 얼마동안 폭로되었을 때 발 생한다고 생각합니까?'에 대한 응답으로 대기업 근로자들은 '아주 잠시 폭로되어도 해롭다' $4 \%$, ‘수 시간 이상 폭로되면 해 롭다' $42 \%$, '수 일 이상 폭로되면 해롭다' $12 \%$, '수년 이상 폭로 되면 해롭다' $4 \%$, '십여 년 이상 폭로되면 해롭다' $31 \%$, 중소기 업 근로자들은 '아주 잠시 폭로되어도 해롭다' $13 \%$, '수 시간 이 상 폭로되면 해롭다' $43 \%$, '수일 이상 폭로되면 해롭다' 13\%, '수 년 이상 폭로되면 해롭다' $30 \%$, '십여 년 이상 폭로되면 해롭다' $0 \%$ 로 응답하였다.

다음으로 10 년 초과 근무자를 기업별로 분석한 결과, 대기업 은 평균 71.50 이었고, 중소기업은 22.83으로 나타나 통계적으 로 유의미한 차이를 보였다 $(t=-5.727, p<0.05)$.

청력보존프로그램 인식 설문지를 문항별로 분석한 결과를 보면, 소음측정 관련 문항(나는 내가 일하고 있는 부서의 소음 수준을 알고 있다, 소음방지 및 청력보호를 위해 소음 측정을 할 필요가 있다)에서 대기업 근로자는 '예' $90 \%$, '아니오' $10 \%$, 중소기업 근로자들은 ‘예' $33 \%$, '아니오' $67 \%$ 로 응답하였다. 청 력측정 관련 문항(나는 지금까지 청력검사를 받은 적이 있다) 에서 대기업 근로자들은 '예’ $54 \%$, '아니오' $46 \%$, 중소기업 근로

Table 3. Comparison of workers whose period of work

\begin{tabular}{|c|c|c|c|c|c|c|}
\hline & \multicolumn{2}{|c|}{ Large firms } & \multicolumn{2}{|c|}{ Medium enterprises } & \multirow{2}{*}{$t$ value } & \multirow{2}{*}{$p$ value } \\
\hline & Mean & Standard deviation & Mean & Standard deviation & & \\
\hline Total awareness for under 10 years & 58.00 & 14.28 & 45.66 & 15.33 & $t=-1.442$ & $p>0.05$ \\
\hline Total awareness for over 10 years & 71.50 & 13.95 & 22.83 & 15.45 & $t=-5.727$ & $p<0.05$ \\
\hline
\end{tabular}


자들은 '예' $46 \%$, '아니오' $54 \%$ 로 응답하였다. 청력보호 관련 문 항(나는 귀마개를 지급받은 적이 있다)에서 대기업 근로자들은 '예' $62 \%$, '아니오' $38 \%$, 중소기업 근로자들은 '예' $7 \%$, '아니오' $93 \%$ 로 응답하였다. 교육 관련 문항(나는 청력보호에 대한 교육 을 받은 적이 있다, 나는 소음에 대한 교육을 받은 적이 있다, 우리나라 산업안전보건법상 8시간 동안 작업을 할 때 소음의 허용 기준은?)에서 대기업 근로자들은 '예' $83 \%$, '아니오' $17 \%$, 중소기업 근로자들은 '예' $17 \%$, '아니오' $83 \%$ 로 응답하였다. 교 육 문항 중 ‘우리나라 산업안전보건법상 소음의 허용 기준은?' 에 대한 응답으로 대기업 근로자들은 ' $80 \mathrm{dBA}$ ' $54 \%$, '90 dBA' $46 \%$, 중소기업 근로자들은 ' $80 \mathrm{dBA}$ ' $22 \%$, '90 dBA' $37 \%$, ' 100 $\mathrm{dBA} ' 41 \%$ 로 응답하였다. 공학적 또는 관리적 소음조절 관련 문항(소음 속 근로시간 추가에 따른 쉬는시간이 제공되거나 교 대근무를 하십니까?)에서 대기업 근로자들은 '예' $77 \%$, '아니오' $27 \%$, 중소기업 근로자들은 ‘예’ $7 \%$, '아니오' $93 \%$ 로 응답하였 다. 기타 문항(나는 귀 때문에 진료를 받은 적이 있다, 직업병은 예방 가능하다, 소음이 건강에 미치는 해로운 영향이 얼마 동 안 폭로되었을 때 발생한다고 생각하십니까?)에서 대기업 근로 자들은 '예' $63 \%$, '아니오' $37 \%$, 중소기업 근로자들은 '예' $27 \%$, '아니오' $73 \%$ 로 응답하였다. 기타 문항 중 '소음이 건강에 미치 는 해로운 영향이 얼마 동안 폭로되었을 때 발생한다고 생각합 니까?'에 대한 응답으로 대기업 근로자들은 아주 잠시 폭로되 어도 해롭다' $11 \%$, '수 시간 이상 폭로되면 해롭다' $42 \%$, '수일 이상 폭로되면 해롭다' 19\%, '수년 이상 폭로되면 해롭다' $15 \%$, '십여 년 이상 폭로되면 해롭다' $11 \%$ 로, 중소기업 근로자들은 '아주 잠시 폭로되어도 해롭다' $0 \%$, ‘수 시간 이상 폭로되면 해 롭다' $41 \%$, '수일 이상 폭로되면 해롭다' $37 \%$, '수년 이상 폭로되 면 해롭다' $22 \%$, '십여 년 이상 폭로되면 해롭다' $0 \%$ 로 응답하 였다.

\section{DISCUSSIONS}

현재까지 청력보존프로그램에 대한 인식과, 대기업과 중소기 업에 따른 비교에 대한 연구는 많이 이루어지고 있지 않는 것 으로 조사되었다. 이에 본 연구는 대기업과 중소기업의 소음환 경에서 근무하는 근로자들의 소음성 난청에 대한 인식 및 청력 보존프로그램에 대한 인식 현황과 이를 비교하는 연구를 수행 하였다. 또한, 이를 통해 우리나라 소음발생 산업장에서 근무 하는 근로자들의 소음성 난청을 예방하기 위한 체계적인 교육 프로그램을 개선·개발하는 것에 기여하고자 진행하였다.

대기업과 중소기업의 청력보존프로그램에 대한 전체 인식 비 교에서는 대기업이 평균 64.00으로 중소기업의 평균 33.83보다 높게 나타났다. 이는 대기업의 근로자에 대한 근무환경 개선에
대한 노력들이 중소기업보다 더 높다는 것을 볼 수 있었으며, 각 세부 문항들에 대한 인식 비교에서도 대부분 대기업에서 높 게 나타났다. 특히 '우리나라 산업안전보건법상 8시간 동안 작 업을 할 때 소음의 허용 기준 문항에서 대기업은 $80 \%$ 이상으 로 전반적으로 잘 알고 있었으나 중소기업은 $24 \%$ 로 세부적인 내용에 대해서는 알고 있는 부분이 아주 적은 것을 볼 수 있었 다. 이는 대기업과 중소기업 청력보존프로그램 자체에 대한 차 이도 있을 것으로 보인다. 대기업에서는 체계적이며 중장기적으 로 프로그램을 잘 구성하여 진행하는 반면, 중소기업에서는 그 럴만한 여력이 되지 않아 법적인 교육 시간만 채우는 경향이 없지 않다. 중소기업이 이러한 부분에서 문제의식을 깨닫고 사 내 공모전이나 재미있는 동영상 강의 등 보다 접근성이 강하고 근로자들이 직접 문제를 깨달을 수 있는 프로그램을 제시한다 면 중소기업 또한 소음성 난청 예방에 대한 인식이 바뀔 것으 로 생각된다.

Kwon et al.(2001)에 의하면 지하철 근로자의 소음성 난청 유소견자 4명 모두 근무기간이 10년 이상이었으나 소음성 난청 요관찰자는 5년 미만 된 근로자에서 9.07\%, 10년 이상 된 근로 자에서 $6.43 \%$ 로 나타나 5 9년 된 근로자에서 요관찰자율이 가장 높은 것으로 나타났다. 본 연구의 결과로 보아 대기업의 경우 청력보존프로그램이 실시되어 전체적인 인식부분에서는 중소기업보다 높았으나 10년 이하의 근로자에서는 통계적으로 유의미한 차이를 보이지 않았다. 하지만, 10 년 이상 근로자에서 는 평균적으로 큰 차이를 보였다. 이는 중소기업에서도 동일하 게 청력보존프로그램을 실시하기는 하지만, 지속적인 관리가 되지 않고, 특히 10년 이상된 근로자인 경우 소음에 대한 인식 부분을 소홀히 여기는 경향이 있음을 발견할 수 있었다. 상대 적으로 대기업은 청력보존프로그램에 대한 인식에 대한 지속적 인 관리가 잘 되고 있음을 볼 수 있다. Lee \& Han(2015)에 의 하면 설문지를 통한 소음성 난청에 대한 인식조사 및 분석에서 연령에 따른 분석결과 젊은 20 30대층 뿐만 아니라 노인성 난 청의 대상이 될 수 있는 연령대인 50 60대에서도 청력 손실이 개인건강에 위험요소로 인식되지 않는다고 한다. 또한 응답자 들은 소음 노출로 인한 청각과 관련된 문제를 겪어 보았지만 청력보호구 사용에 대해서는 부정적인 견해를 보이고 있다. 본 연구 결과, 중소기업에서 10 년 미만과 초과 근무자 모두 청력손 실에 대한 교육과 청력보호구 사용의 필요성 인식이 낮은 것으 로 나타났다.

본 연구의 제한점으로는 다양한 대기업, 중소기업 근로자에 대해서 조사를 실시하였으나 대기업 근로자 50명, 중소기업 근 로자 50명을 표본으로 실시한 설문을 통해 얻은 결과로, 집단 을 대표하기에는 표본수가 부족 하였고, 설문 요인 및 문항들 이 표준화되지 못한 척도이기 때문에 본 설문지를 산업 현장에 
그대로 사용하기에는 무리가 있다. 또한 단순히 대기업과 중소 기업을 비교하기만 하였을 뿐 표준화를 도출하지 못했기 때문 에 기준 점수를 알 수 없다. 향후 좀 더 많은 표본수를 확보하 고, 설문지를 표준화하여 기준 점수까지 설정한다면 청력보전 프로그램에 대한 인식 및 소음의 위험 인지에 대한 유용한 설 문지가 될 것으로 생각된다. 또한 대기업과 중소기업의 $\mathrm{HCP}$ 에 대한 내용 및 최초시행시기 또는 시행 기간 및 지속적 시행 여 부 등을 알 수 있다면 보다 구체적인 비교 연구가 가능할 것으 로 보이므로 향후 연구에서는 기업에 이런 부분을 요청하여 추 가 연구가 진행되면 더 좋은 것으로 보인다.

Kwak et al.(1997)에 의하면 청력 교육을 실시하고, 청력 보 호구를 착용했던 기업의 근로자 집단에서 그렇지 않은 집단보 다 청력이 더 좋았다는 연구 결과가 있었다. 본 연구와 더불어 보았을 때 청력보존프로그램의 교육과 보장구의 착용이 소음 성 난청을 유발하는 데 영향이 있는 것으로 보인다. 따라서 지 금까지의 청력보존프로그램으로 사용된 동영상 강의, 유인물 등이나 일방적인 강의 등을 사용하는 것보다는 향후 대기업, 특히 중소기업에서 체계적이며 근로자들로 하여금 흥미를 유 발시키며 자발적으로 자신의 청력을 보존할 수 있는 청력보존 프로그램을 도입한다면 소음성 난청을 줄일 수 있는 큰 전환점 이 될 수 있을 것이다.

중심 단어 : 소음성 난청·청력보존프로그램·청력보호인식.

\section{REFERENCES}

Choi, H. R. \& Lee, W. C. (1996). Knowledge and attitude towards the noise-induced hearing loss of the workers with hearing impairment in the noisy workplace. Korean Journal of Occupational and Environmental Medicine, 8(1), 105-118.

Kang, Y. S. (2000). Risk perception associated with noise exposure on pilots and ground-crews in the Korean Air Force (unpublished master's thesis). Yonsei University, Seoul.

Kim, K. S. (2006). Disturibution of hearing thresholds and hearing loss among noise-exposed workers. Korean Journal of Communication Disorders, 11(2), 106-121.

Kwak, M. S., Lee, J. T., Kim, J. H., Urm, S. H., Kim, D. H., Son, B. C., et al. (1997). Evaluation on hearing conservation program in the noisy industries. Korean Journal of Preventive Medicine, 30(4), 815-829.

Kwon, H. J. (2010). A study on a self hearing test to prevent noise induced hearing loss (unpublished master's thesis). Soongsil University, Seoul.

Kwon, Y. J., Lee, S. J., \& Song, J. C. (2001). A study on noise induced hearing loss of employees working for Seoul metropolitan subway cooperation. Korean Journal of Aerospace and Environmental Medicine, 11(1), 37-44.

Lee, D., Yu, J., \& Han, W. (2015). Evaluation and analysis of awareness in noise-induced hearing loss using survey. The Journal of the Acoustical Society of Korea, 34(4), 274-281.

Lee, J. H. (2010). Occupational diseases of noise exposed workers. Hanyang Medical Reviews, 30(4), 326-332. 
APPENDIX

\section{소음 속 근로자들의 청력보호프로그램 인식조사}

A Study on the Analysis of Hearing Conservation Programs

\begin{tabular}{|ll|ll|ll|ll|}
\hline 연 & 령 & 만 & 세 & 성 별 & (1) 남 (2) 녀 \\
\hline 회 & 사 & 명 & & & 근로 년 수 & \\
\hline
\end{tabular}

\section{아래의 질문에 $\vee$ 표시로 대답하십시오.}

1. 나는 내가 일하고 있는 부서의 소음수준을 알고 있다.
(1) 예
(2) 아니오

2. 소음방지 및 청력보호를 위해 소음 측정을 할 필요가 있다.

(1) 예 (2) 아니오

3. 나는 귀마개를 지급 받은 적이 있다.
(1) 예
(2) 아니오

4. 나는 귀 때문에 진료를 받은 적이 있다.
(1) 예
(2) 아니오

5. 나는 지금까지 청력검사를 받은 적이 있다.
(1) 예
(2) 아니오

6. 나는 청력검사에서 귀가 나쁘다고 애기들은 적이 있다.
(1) 예
(2) 아니오

7. 나는 청력보호에 대한 교육을 받은 적이 있다.
(1) 예
(2) 아니오

8. 나는 소음에 대한 교육을 받은 적이 있다.
(1) 예
(2) 아니오

9. 우리나라 산업안전보건법상 8시간 동안 작업을 할 때, 소음의 허용기준은?
(1) $80 \mathrm{~dB}$
(2) $90 \mathrm{~dB}$
(3) $100 \mathrm{~dB}$
(4) $120 \mathrm{~dB}$

10. 직업병은 예방 가능하다.
(1) 예
(2) 아니오

11. 소음이 건강에 미치는 해로운 영향이 얼마동안 폭로되었을 때 발생한다고 생각하십니까?
(1) 아주 잠시 폭로되어도 해롭다.
(2) 수 시간 이상 폭로되면 해롭다.
(3) 수일 이상 폭로되면 해롭다.
(4) 수년 이상 폭로되면 해롭다.
(5) 십 여 년 이상 폭로되면 해롭다.

12. 소음 속 근로시간의 추가에 따른 쉬는 시간이 제공되거나 교대근무를 하십니까?
(1) 예
(2) 아니오 